\title{
The Impact of Transit-Oriented Shopping Mall Developments (TOSMDs) on Metro Station Ridership: Dubai Metro Redline
}

\author{
Ayman Abutaleb $^{1}$ (1) Kevin McDougall $^{2}$ (1) Marita Basson $^{2}$ (1) $\cdot$ Rumman Hassan $^{3}$ • \\ Muhammad Nateque Mahmood $^{4}$ (1)
}

Received: 25 December 2019/Revised: 23 March 2020/Accepted: 4 May 2020/Published online: 15 July 2020

(C) The Author(s) 2020

\begin{abstract}
Transit-oriented shopping mall development (TOSMD) is a novel concept in urban planning practice. The array of TOSMD attractiveness factors is not currently included in the forecasting models for station ridership. As a result, a station near a TOSMD can reach its capacity because its design and development didn't take into account TOSMD, while TOSMD contributes passenger flow to the station. Depending on the setting, the number of visiting tourists could exacerbate this problem. Therefore, this study aims to empirically identify the critical TOSMD
\end{abstract}

Electronic supplementary material The online version of this article (https://doi.org/10.1007/s40864-020-00129-0) contains supplementary material, which is available to authorized users.

Ayman Abutaleb

aymanabutaleb@hotmail.com

Kevin McDougall

Kevin.McDougall@usq.edu.au

Marita Basson

Marita.Basson@usq.edu.au

Rumman Hassan

Rumman.Hassan@usq.edu.au

Muhammad Nateque Mahmood

n.mahmood@deakin.edu.au

1 RTA - Rail Agency (CEO Office), P. O. Box 118899, Dubai, UAE

2 School of Civil Engineering and Surveying, University of Southern Queensland, Toowoomba, Australia

3 School of Management and Enterprise, University of Southern Queensland, Springfield, Australia

4 School of Architecture and Built Environment, Deakin University, Geelong, Australia

Communicated by Min Zhang. attractiveness factors and clarify their impact in terms of shopper passengers contributing to the ridership at stations near TOSMDs in the case of the Dubai Metro Redline. A sample of 700 shopper passengers were surveyed at seven stations near TOSMDs. We used principal component analysis with confirmatory factor analysis, and structural equation modelling to explain the impact of TOSMD attractiveness on shopper passenger ridership at stations near TOSMDs. Eleven independent TOSMD attractiveness factors were found to be associated with the extent of shopper passengers' intention to use a station near a TOSMD. Resident and tourist shopper passengers showed variability in the factors impacting their use of stations near TOSMDs. The study assists in empirically validating the impact of TOSMD attractiveness on ridership at stations near TOSMDs, as a means of increasing the economic sustainability of transit networks. It provides statistically fit models for clarifying the generated resident and tourist shopper passenger ridership contributing to a station ridership as a result of its nearby TOSMDs. For a more comprehensive analysis, future studies could be repeated for transit networks in other cities.

Keywords Transit-oriented shopping mall development . TOSMD - Attractiveness factors - Station use - Passenger forecasting models

\section{Introduction}

The growth rates of gross leasable area (GLA) of shopping malls in countries such as the USA, Russia, France, and Turkey have been continuously increasing [1]. However, a US report released by Cushman \& Wakefield [2] showed that in the USA, while there were more than 4000 major 
chain closures during 2016 however, consumers were still attracted to grocery stores, dollar stores, and dining experiences. Changes in shopping mall attractiveness factors can contribute to fluctuating patterns of growth in different areas of shopping mall development, and have increased the focus on mixed-use models in future and redeveloped malls. A mixed-use transit-oriented shopping mall development (TOSMD) refers to a shopping mall (SM) near a rail transit station in a transit-orientated development (TOD) context, where shoppers drive their cars less and instead ride nearby mass transit [3]. Major components of a shopping mall can include stores, food courts, restaurants, cinemas, children's play areas, interactive entertainment, social use areas, relaxation spaces, and promotional areas [4]. Therefore, the development of TOSMDs can contribute to making areas surrounding a rail station more attractive, and could potentially increase the ridership of shopper passengers using the transit station near a TOSMD.

A transit station near a TOSMD can reach capacity in a short time as a result of congestion in a nearby shopping mall [5], resulting in costly upgrades and disruption to the rail service and travellers. In addition, population growth in cities, as well as visiting tourists, can exacerbate this problem. Hence, there is a need to understand the impact of TOSMD attractiveness on the ridership of passengers using a nearby transit station and its capacity to serve boarding shopper passengers.

Our understanding of transit station use as a result of TOSMD attractiveness is limited. Furthermore, the potential benefits of coordinated transportation and land-use planning through TOD are sometimes not adequately considered [6], particularly in the case of TOSMDs. Our previous study proposed a framework for TOSMD attractiveness factors [3]. It used the seven elements of the extended service marketing mix (product, price, place, promotion, people, physical evidence, and process) and the five factors related to TODs (density, diversity, urban design, destination accessibility, and distance) to understand transit station use by shopper passengers as a result of TOSMD attractiveness. However, this framework has not been empirically examined. Therefore, this paper empirically examines the impact of TOSMD attractiveness factors.

The study attempts to link and predict the contribution of those attractiveness factors, in the form of the shopper passenger ridership, to the ridership of a nearby transit station in the case of Dubai Metro Red Line stations. Other level-of-service factors (such as punctuality, availability, public transport policies, and fare level) are neutralised by selecting the same geographical context, namely Dubai Metro Red Line in the United Arab Emirates (UAE). To achieve this goal, the study investigates the research question: "How do TOSMD attractiveness factors impact the ridership in a nearby transit station?" To understand this relationship, the study has the following three objectives:

- To review transit passenger forecasting models (PFMs) and station boarding factors (SBF)

- To review the capture of TOSMD attractiveness factors and the ridership of tourist shopper passengers (TSPs) in PFMs

- To compare and determine how the ridership of shopper passengers (both tourists and residents) boarding at a station near a TOSMD changes with TOSMD attractiveness factors, using seven Dubai Metro Red Line metro stations near TOSMDs.

The study is organised as follows: Sect. 2 presents a review of the existing literature relevant to transit passenger forecasting models (PFMs), station boarding factors (SBF), TOSMD attractiveness factors, and tourist shopper passenger (TSP) ridership for transit stations. Section 3 presents the methodology and data analysis techniques. Section 4 presents and discusses the results of the study, and finally, the last section concludes with the implications of the findings, limitations, and proposed further research.

\section{Literature Review}

\subsection{Introduction}

Several studies have been conducted to evaluate and clarify the driving factors behind metro station ridership and station boarding [8-10]. Statistical models have been used to develop passenger forecasting models (PFMs) relating transit stations as a function of the station's environment and the transit features [12-13]. These models have applications such as forecasting the potential station ridership along transit corridors, identifying the factors contributing to station boarding, optimising transit station design, and planning future expansions and design modifications. Therefore, to achieve the study objectives, this section reviews the current literature relating to PFMs, station boarding factors (SBFs), TOSMDs captured in PFMs, and tourist shopping passengers (TSPs) captured in PFMs

\subsection{Transit Passenger Forecasting Models (PFMs)}

Traditionally, urban planners have used McNally's [14] regional four-step travel forecasting models, which consider trip generation, distribution, mode choice, and route assignment. This method is used despite complexity and accuracy issues, incomplete travel input data (estimation is typically based on relatively old household surveys, which 
may include a small number of transit trips in the area of interest), insensitivity to land use, and institutional barriers to consultation and collaboration (transit providers are often not part of the modelling process), in addition to being cumbersome and expensive [15].

Direct models have therefore been developed based on multiple regression analysis as a complementary approach for estimating ridership [12-13, 15]. Such models are a less complicated and less expensive alternative to the four-step models. They are also directly responsive to land-use characteristics within the station catchment areas. However, direct models lack the regional perspective of the four-step models. In determining the variables impacting station ridership, researchers such as Choi et al. [16] have investigated metro ridership at the station level and the station-to-station level and concluded that ridership factors could be the same. Drawing circular catchments showing prospective passenger areas and GIS mapping approaches [17] have been used in determining the space located near railway stations with a view towards increasing their density so as to increase the number of potential train users. Chakour and Eluru [18] recently added that time to travel to a station is a significant factor negatively impacting the choice of a station and ridership, respectively. Policies can also influence users of public transport. Handy [19] and Vessali [20] indicated that factors such as zoning and restrictions on parking could play a significant role in the success of the TOD urban planning concept, and hence could also play a significant role in a TOSMD.

The following two approaches were identified to summarise the recent approaches to station ridership forecasting. The first approach examines a station-to-station (origin-destination matrix) ridership as the basis for the station ridership forecast, whilst the second explores station-level ridership-weighted variables (distance-decayweighted regression). The origin-destination (O-D) matrix [21] utilises an automatic fare collection (AFC) system data to infer rail passenger trip O-D matrices from an origin to replace expensive passenger O-D surveys. The distance-decay-weighted regression approach [15] applies weights to a range of variables affecting the station ridership; including characteristics of the stations (type, number of lines, accessibility within the network), and the areas it serves (population and employment characteristics, landuse mix, street density, presence of feeder modes) according to the distance-decay functions. Prior direct ridership models at the station level used fixed distance thresholds. They did not reflect the impact on travel of concentrated housing and employment at a longer/shorter distance from the station in cases where these developments were located within the station catchment area.

In conclusion, while many other factors influence transit ridership, population density, employment density, land- use mix, walking accessibility, transit accessibility, automobile accessibility, and central business district (CBD) characteristics are among the most consistently studied factors by forecasters [22]. Furthermore, including these variables in PFMs addresses the shortcomings of the fourstep model. Additionally, these factors deal with the built urban environment, transportation policy, and alternatives to the automobile and social factors influencing transit ridership.

\subsection{Station Boarding Factors (SBFs)}

Sohn and Shim [10] referred to three categories of station boarding factors (SBFs), including (1) built environment, (2) external connectivity, and (3) intermodal connection. These three categories contained 24 metro boarding independent variables identified from previous studies [12-13, 24-29]. Among those identified, seven variables were significantly associated with station boarding, namely employment, commercial floor area, office floor area, net population density, the number of transfers, the number of feeder bus lines, and a dummy variable indicating transfer stations.

However, Sohn and Shim [10] and several other researchers [11, 15, 23, 31-34] did not drill down into the sub-variables of the "commercial floor area". Therefore, there is a need to investigate these sub-variables, specifically in the case of TOSMDs, to improve the accuracy of PFMs at transit stations near TOSMDs for optimal TOD and to increase the economic benefits for transit networks.

\subsection{TOSMD Attractiveness Factors}

Shopping malls have become a significant element in the urban landscape, as better mobility can improve cities' economies, tourism intensity [35], and place marketing. Place marketing means designing a place to satisfy the needs of its target markets [36]. It implies creating competitive market offerings that can better satisfy the city's target market needs [38-42]. Historically, Huff [43] assumed that the centripetal power exercised by a shopping mall was directly proportional to the size of the retail centre and inversely proportional to the consumer's distance or travel time to the shopping mall. A large shopping mall tends to provide a wider product assortment. Distance, however, represents a cost or disutility to the consumer [44]. Nevin and Houston [44] categorised shopping area attributes into three dimensions, namely assortment, facilities, and market posture. Wong et al. [45] increased the number of shopping mall attributes from the 16 originally identified by Nevin and Houston [44] to 21 factors. These 21 attributes fall under five dimensions, namely (1) location, including convenient location, located at retail belt; 
(2) quality and variety, including owner's reputation, merchandise quality, service quality, merchandise variety, service variety, general price level; (3) popularity, including uniqueness, fashion; (4) facilities, including parking facilities, adequate and well-designed vertical transport, store atmosphere, layout, resting seats; and (5) sales incentives, including availability of supermarket, sales promotion, food court, special events/exhibit, and late closing hours.

The majority of shopping mall attractiveness studies have focused on attributes of shopping malls within the shopping mall context, to predict and optimise mall patronage [46, 47], identifying the optimal mix of activities in shopping malls, developing retailing strategies [49-51], understanding socio-spatial dynamics [52], and determining mall rent [53].

However, in order to optimise the potential benefits of coordinated transportation and land-use planning particularly in the case of TOSMDs, there is a need to analyse the impact of the internal and external attractiveness factors of TOSMDs [3, 6, 54]. Therefore, the TOSMD's internal attractiveness factors of product, price, place, promotion, people, physical evidence, and process, and the external attractiveness factors of density, diversity, urban design, destination accessibility, and distance need to be empirically examined [3], to identify which attractiveness factors contribute to ridership in the form of shopper passengers boarding at metro stations near TOSMDs.

\subsection{Tourist Shopper Passengers (TSPs) Captured in PFMs}

Passenger forecasting models (PFMs) tend to pay less attention to tourist passengers. Therefore, city planners sometimes do not consider the number of tourist arrivals in their studies as a factor in the design of transit supply. They tend to extend the benefit of visiting tourists by keeping the supply of public transport at the same level and tolerating a certain degree of congestion during tourist seasons [35]. Hall [55] indicated four roles of transport for tourists: first, linking the market of origin with the tourist destination; second, providing access and mobility within a wide destination area (region or country); third, offering access and mobility within a tourist attraction or destination; and fourth, providing travel along a recreational route.

Albalate and Bel [35] noted that studies had given less attention to the factors impacting the third role identified by Hall [55]. They provided guidance for factors impacting tourist transit passengers (TTP), as illustrated in Fig. 1.

Therefore, tourist shopper passengers (TSPs), as part of TTPs, are captured to a lesser extent in PFMs.

In conclusion, transit PFMs tend to ignore transit shopper passengers (residents or tourists) in their models.
Hence, this study addresses the identified gap for TOSMDs and empirically examines to what extent attractiveness factors of TOSMDs impact ridership in the form of resident and tourist shopper passengers boarding at transit stations near TOSMDs.

\section{Methods}

This research was designed to identify and clarify the salient TOSMD-related attractiveness factors that affect the ridership caused by shopper passengers (unit of analysis) on the Dubai Metro Red Line stations where a TOSMD exists nearby. A survey was undertaken to gather data on shopper passengers at these stations. This method was selected as it was relatively easy for passengers to understand and complete, and was capable of producing a large volume of data in a limited period, and its results could be used for statistical analyses [56, 57]. Shopper passengers (individuals) boarding at seven metro stations near TOSMDs were surveyed to understand their perspectives on shopping mall attractiveness and ridership preferences. Structural equation modelling (SEM) was used to clarify the impact of the identified TOSMD attractiveness factors on the ridership of shopper passengers. Figure 2 provides an overview of the steps taken in this study.

\subsection{Case Study Area}

Dubai is an example of a city which has sought to differentiate itself as a shopping hub, and has more than 65 shopping malls [58]. The city has an area of only $4114 \mathrm{~km}^{2}$ [59] and a population of 3.3 million [60]; however, it was visited by 15.92 million visitors in 2018 [61]. The large number of visitors to Dubai shopping malls are located near the city's domestic Metro Red Line.

The Dubai Metro Red Line, also called Phase (1), is 52.1 kilometres long and was opened in 2009. It has two stations connected to Dubai airport (T1, T3) and a number of stations connected or adjacent to (within around $0.8 \mathrm{~km}$ radius) large shopping malls. These stations are circled in Fig. 3 and include (from left to right) Ibn Battuta Mall, Dubai Marina Mall, Mall of Emirates, Dubai Mall, BurJuman Shopping Centre, Al Ghurair Centre, and Deira City Centre. These malls are typically in high-density, mixed communities along Sheikh Zaid Road and the old Deira area. The Dubai Metro Red Line stations include urban-designed walkways which connect the mall and a nearby metro station.

The number of passengers checking in at Dubai Metro Red Line stations during the period from 2013 to 2018 (the period when there were no major changes in the line services) is depicted in Fig. 4. 
Fig. 1 Tourist transit passengers factors Adapted from Albalate and Bel [35]
- The fleet of vehicles available for public transport (FLEET)

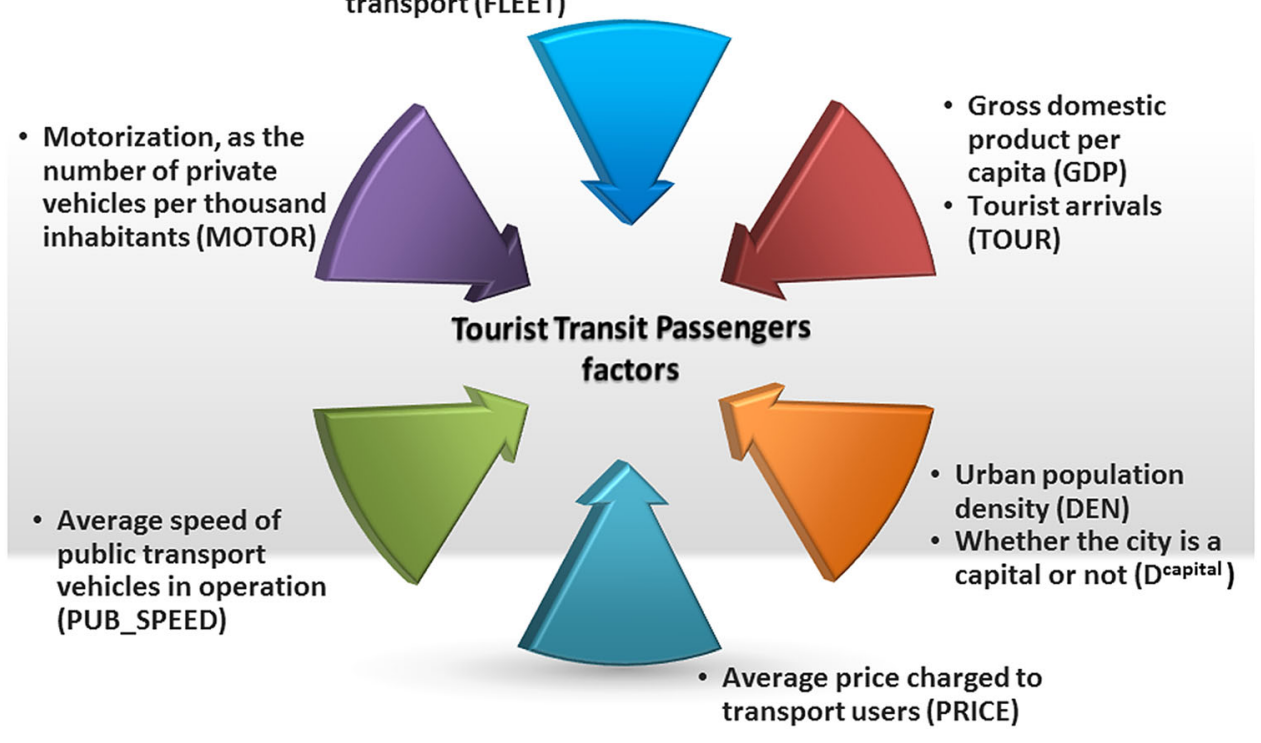

\begin{tabular}{|c|c|c|}
\hline \begin{tabular}{ll} 
& \multicolumn{1}{c}{ Data collection } \\
- & $\begin{array}{l}\text { Dubai Metro Red Line route } \\
\text { map }\end{array}$ \\
- & $\begin{array}{l}\text { Stations' Checking-in } \\
\text { passengers' data }\end{array}$ \\
- & $\begin{array}{l}\text { Instrument/measures } \\
\text { development }\end{array}$ \\
- & Respondents selection \\
- & Pilot study (pre-testing) \\
- & Refinement of the \\
instrument/measures \\
- & Collection of data
\end{tabular} & \begin{tabular}{ll}
\multicolumn{1}{c}{ Analysis } \\
- & $\begin{array}{l}\text { Exploring TOSMD's } \\
\text { attractiveness factors }\end{array}$ \\
- & Confirming identified factors \\
- & Validity/Analysis \\
- & $\begin{array}{l}\text { Exploring relationships and } \\
\text { significance }\end{array}$
\end{tabular} & \begin{tabular}{ll} 
- & \multicolumn{1}{c}{ Results } \\
- & Implindings \\
- & Limitations
\end{tabular} \\
\hline
\end{tabular}

Fig. 2 Research method

As can be seen in Fig. 4, Dubai Metro Red Line stations near the TOSMDs generally have higher numbers of passengers checking in. This study uses the Dubai Metro Red Line as a single case rather than a comparison of different sub-cases, as there are few studies directly addressing the study problem within a homogeneous, one-study context capturing the relationship between metro station use and the attractiveness of TOSMDs. Although the case study methodology, particularly the single case, is inconsistent with the requirements of generalisation [62, 63], Yin [64] and Flyvbjerg [65] identify the value of using typical cases in analytical generalisation and the ability of a theory to be tested in a similar theoretical setting to further define its explanatory power [66]. Hence, this study provides a practical opportunity to identify and clarify the impact of TOSMD attractiveness factors on ridership at transit stations near TOSMDs along the Dubai Redline, and could be repeated for transit networks in other cities.

\subsection{Data Collection}

The data used to examine the station use by shopper passengers and the attractiveness factors of TOSMDs and the variables in the modelling were collected from various sources. The number of passengers checking in at each station of the Dubai Metro Red Line were obtained from the Rail Operations Department, Road and Transport Authority (RTA), which is responsible for the operation of Dubai Metro. The seven TOSMDs were identified using GIS and Google Maps based on a walkable distance around $0.8 \mathrm{~km}[11,15,67,68]$. The initial list of independent TOSMD attractiveness factors was synthesised from the literature review (refer to Sect. 2.4). The study used data 


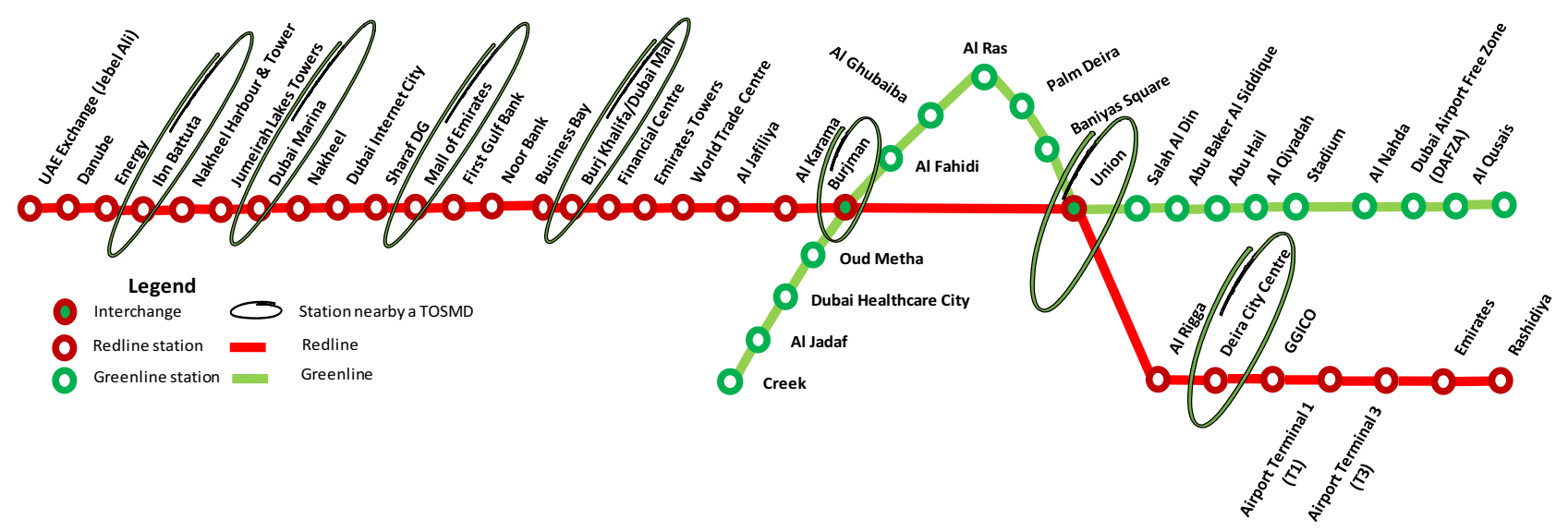

Fig. 3 Dubai Metro Red Line route map and stations within $0.8 \mathrm{~km}$ (circled) of the shopping malls

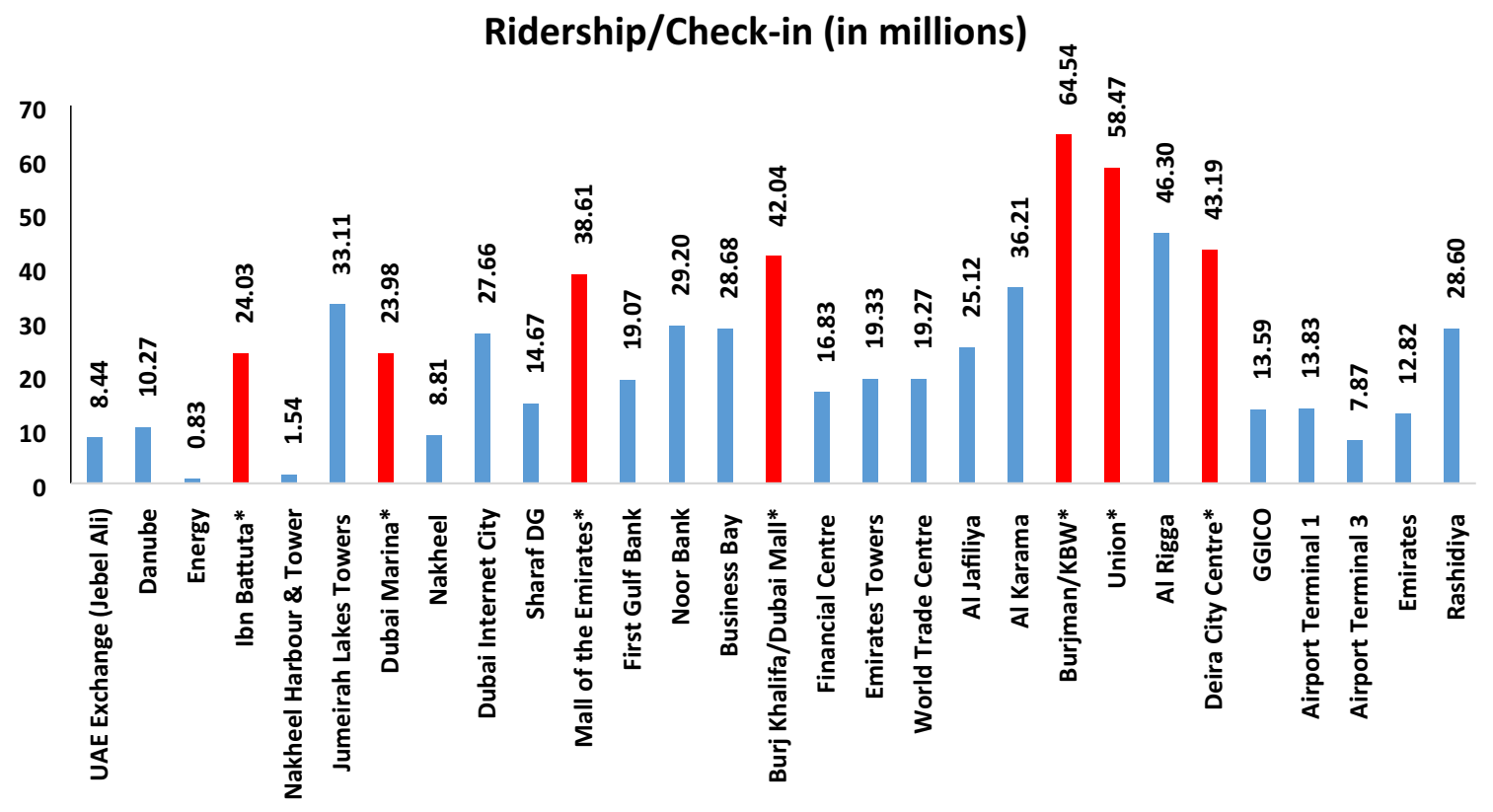

Fig. 4 Number of passengers checking in at stations of the Dubai Metro Redline during the period from 2013 to 2018 Source: Rail Operations Department (RTA) Database for Dubai Metro operations from 2013 to 2018

collected from a 72-question survey (refer to the Online Appendix). The survey was divided into six sections addressing demographic and behavioural characteristics of the respondent shopper passengers. It measured the importance of a shopping mall and its neighbourhood characteristics impacting passengers' decisions to visit the mall near a metro station, using a five-point Likert scale [49, 69]. The survey questionnaire was pre-tested using a collaborative participant pre-testing method [70] with a sample of 10 shopper passengers.

Data for the main study was collected daily during the period from April 2019 to October 2019. The survey was mainly distributed during the afternoon daily peak time between 4:00 pm and 8:00 pm by sampling conducted at the seven metro stations near shopping malls, as shown in Fig. 3. It was determined that the survey period and the afternoon data collection time provided the greatest diversity of participants, including workers and their families. Participants were purposively selected based on first asking the shopper passengers if they had come from the shopping mall to board the metro at the nearby station [71]. If the answer was "yes", these shopper passengers were asked to participate in the survey. The daily morning peak time between 6:00 am and 9:00 am was avoided since shopping mall shops commonly open after 9:00 am. Therefore, target shopper passenger prospective 
respondents were not available during this time. Shopper passengers were given the option to complete the survey on a paper based form or using a given web link to the study survey. Out of 1200 surveys distributed, 700 survey responses were received (response rate $=58 \%$ ), including 366 online completed survey responses (52\%) and 334 completed forms of survey responses $(48 \%)$.

The data obtained from the 700 surveyed shopper passengers was used to explore the principal list of attractiveness factors of TOSMDs, which was used to construct the SEM model explaining the impact of TOSMD attractiveness factors on the shopper passenger ridership using Dubai Metro Red Line stations near TOSMDs.

\subsection{Descriptive Statistics}

Of the 700 surveyed shopper passengers boarding at the seven metro stations near TOSMDs (see Fig. 3), 69\% were identified as residents and $31 \%$ tourists of Dubai, $47 \%$ were men and 53\% women, and 54\% were aged 18-34 and 46\% older than 34. Twelve independent variables were identified and analysed based on TOSMD attractiveness factors (refer to Sect. 2).

Table 1 presents a profile of the 700 respondent shopper passengers (including residents, tourists, and both) in terms of the level of importance of factors of TOSMD attractiveness and the level of agreement to potentially use a metro station near a shopping mall. The table shows the comparative mean $(M)$ and standard deviation (SD) scores of resident and tourist shopper passengers. As can be seen in Table 1, more than half the respondent shopper passengers ranked a TOSMD's internal attractiveness factors as important or very important, including: product $(M=4.229 ; \mathrm{SD}=0.602)$, price $(M=4.115 ; \mathrm{SD}=0.549)$, place $(M=3.928 ; \mathrm{SD}=0.576)$, promotion $(M=3.96$; $\mathrm{SD}=0.562)$, people $(M=4.294 ; \mathrm{SD}=0.517)$, physical evidence $\quad(M=4.226 ; \quad \mathrm{SD}=0.544), \quad$ and process $(M=3.872 ; \mathrm{SD}=0.616)$. Resident shopper passengers (RSPs) mean score (3.97) for the promotion factor was slightly higher than its equivalent for tourist shopper passengers (TSPs) (3.939). However, TSP mean scores for product (4.268), price (4.116), place (4.002), people (4.312), and physical evidence (4.277) were generally higher than their TSP equivalents for product (4.211), price (4.114), place (3.895), people (4.285), and physical evidence (4.203).

Similarly, a high percentage of respondents ranked TOSMD external attractiveness factors as important or very important, including density $(M=3.554 ; \quad \mathrm{SD}=$ $0.988)$, diversity $(M=3.531$; $\mathrm{SD}=0.767)$, urban design $(M=3.987 ; \quad \mathrm{SD}=0.634), \quad$ destination accessibility $(M=4.091 ; \mathrm{SD}=0.582)$, and distance $(M=3.822 ; \mathrm{SD}=$ 0.75). RSP mean scores for urban design (3.988) and destination accessibility (4.103) were higher than the equivalents for TSPs (3.983 and 4.067, respectively). However, TSP mean scores for density (3.653), diversity (3.565), and distance (3.825) were higher than their RSP equivalents for density (3.509), diversity (3.515), and distance (3.821).

Nonetheless, a high percentage of respondents agreed with the intention to use the metro station close to a mall $(M=3.462 ; \quad \mathrm{SD}=0.864)$ including $\mathrm{RSPs}(M=3.553$; $\mathrm{SD}=0.863)$ and TSPs $(M=3.263 ; \mathrm{SD}=0.833)$. This high percentage was explained in particular by the availability of walking access from the station to the mall $(M=4.09$; SD $=0.997)$, with RSP mean scoring of 4.141, higher than TSPs (3.977).

\subsection{Analytical Approach}

This study mainly explores the impact of TOSMD attractiveness factors on ridership among shopper passengers boarding at transit stations near TOSMDs. We used a principal component analysis (PCA) approach in measuring the impact of these factors and assessing measurement validity, similar to other studies such as El-Adly [49]. The TOSMD attractiveness factors were the independent constructs, and ridership of shopper passenger boarding at a nearby transit station was the dependent construct.

The statistical data for the Dubai Metro Red Line indicated that stations next to shopping mall developments generally have higher ridership than many other stations. The data provided by the shopper passengers was analysed according to the level of importance they attributed to the identified TOSMD attractiveness factors, and their ridership preference for using a metro station near a shopping mall. Confirmatory factor analysis (CFA) was then used to validate the outcome of the PCA analysis, following the empirical model presented by Sohn and Shim [10], which examined on-boarding factors affecting demand at a station level. Similar to Sohn and Shim [10], structural equation modelling (SEM) was conducted to ultimately identify and clarify the impact of TOSMD attractiveness factors on shopper passenger ridership using stations near TOSMDs.

\section{Analysis and Results}

\subsection{Attractiveness Factors of TOSMDs}

Principal component analysis (PCA) showing the salient TOSMD attractiveness factors is displayed in Table 2. It shows that 39 items explain $75.07 \%$ of data variability, with reliability of Cronbach $\alpha=0.821$ and $>0.7$ for each factor. Furthermore, 13 items (i.e. q0019: grocery store presence, q0024: prices offer value for money, q0030: 
Table 1 Internal and external attractiveness factors of TOSMDs $(n=700)$

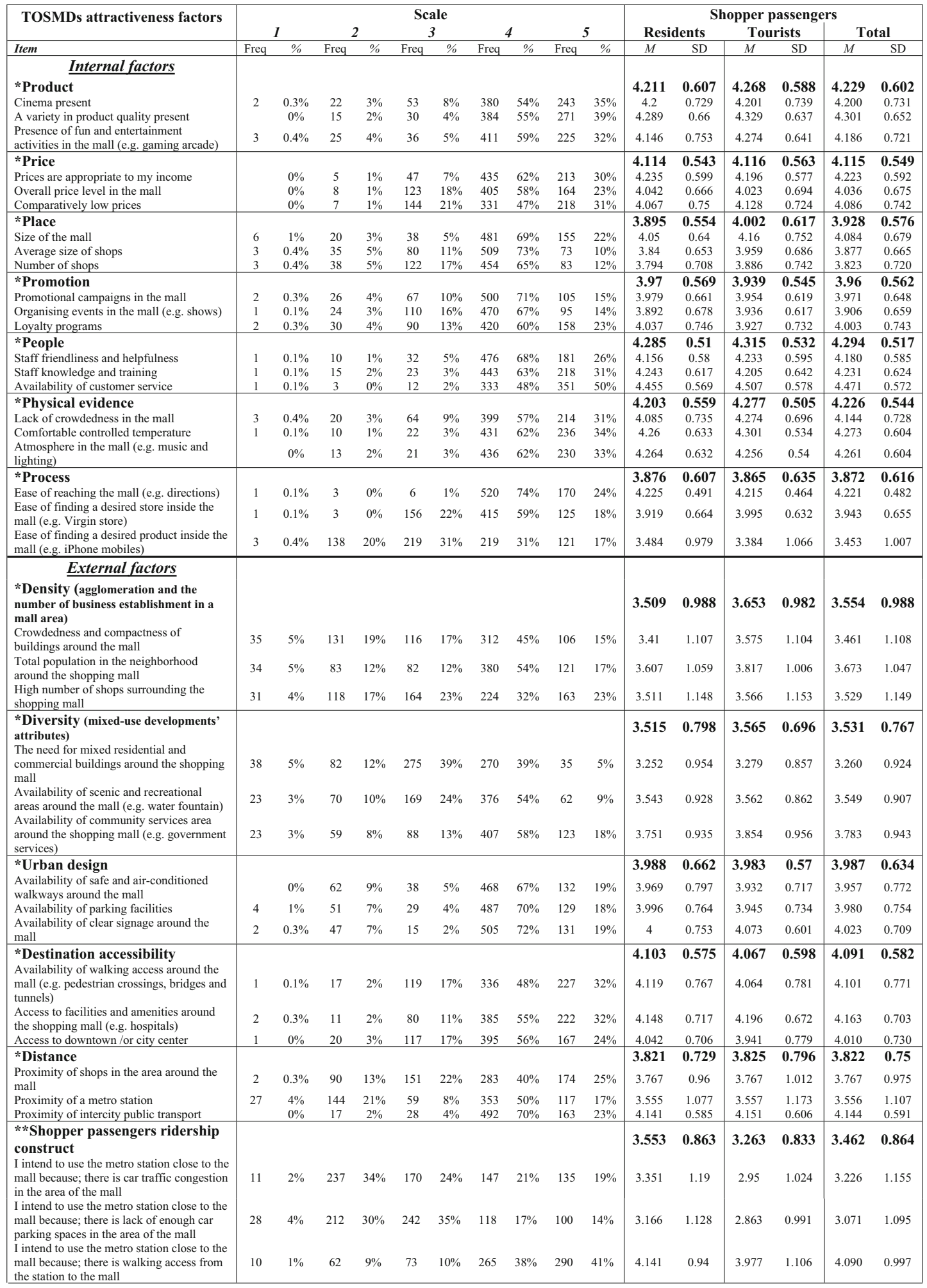

*Scale values range from 1 ("not important") to 5 ("very important")

**Scale values range from 1 ("strongly disagree") to 5 ("strongly agree"): the higher the mean, the higher the attractiveness of that particular aspect

$M$ mean, SD standard deviation, Freq frequency 
convenient facilities and amenities, q0034: mall image and publicity, q0038: staff extended working hours, q0040: modern mall internal decoration, q0046: freedom in the mall, q0049: car traffic congestion around the shopping mall, q0054: economic diversity in the neighbourhood around the shopping mall, q0056: availability of cycling lanes around the mall, q0062: access to different transport mode options, q0066: proximity of other modes of transport, q0067: I intend to use the metro station close to the mall because the station is at a walkable distance from the mall) were excluded from the analysis, as they were not significantly loaded (less than 0.5 ) to any of the 13 revealed constructs [3]. These 13 constructs were product, price, place, promotion, people, physical evidence, process, density, diversity, urban design, destination accessibility, distance, and shopper passenger ridership at the station.

\subsection{Confirmatory Factor Analysis (CFA) and Structural Equation Model (SEM)}

Confirmatory factor analysis was conducted to validate the identified attractiveness factors of TOSMDs impacting the ridership of shopper passengers using stations near a TOSMD [72]. According to Lei and Wu [73], a model is well specified and valid if the sample is large enough, and the normed fit index (NFI), comparative fit index (CFI), and goodness-of-fit index (GFI) are over 0.9 [74, 75]. The study's model showed a reasonable fit [76]: $\chi^{2}=2950$ $(P=0.00)$, degrees of freedom $(\mathrm{DOF})=1005$, goodnessof-fit index $(\mathrm{GFI})=0.9$, the adjusted goodness-of-fit index $(\mathrm{AGFI})=0.83$, the comparative fit index $(\mathrm{CFI})=0.9$, the normed fit index $(\mathrm{NFI})=0.9$, and the root mean square residual $(\mathrm{RMR})=0.054$.

However, attractiveness factors of TOSMDs vary from one context to another (refer to Sect. 2.4). Therefore, in line with Sohn and Shim [10], SEM was then used to examine the causal impact of the attractiveness factors of TOSMDs on the shopper passenger ridership (including RSPs and TSPs). Table 3 shows the regression weights of TOSMD attractiveness factors impacting all shopper passenger ridership (including residents and tourists) boarding-in at Dubai Metro Red Line stations near TOSMDs. The $r^{2}$ is 0.31 for the ridership of all shopper passengers using Dubai Metro Red Line stations near TOSMDs $\left(r^{2}=0.39\right.$ for RSPs, and 0.35 for TSPs). Price $(0.20)$, place $(0.14)$, people $(0.016)$, and density $(0.35)$ factors positively impact the ridership of all shopper passengers. However, the promotion factor shows a negative impact $(-0.35)$ on the ridership of all shopper passengers. Furthermore, product, physical evidence, diversity, urban design, and destination accessibility factors are not significantly associated with the ridership of all shopper passengers. Table 3 also shows variability in the TOSMD attractiveness factors impacting the ridership of RSPs and TSPs. While place (0.14), people (0.18), and distance (0.17) factors are associated with the ridership of RSPs, they are not associated with the ridership of TSPs. However, the product $(-0.19)$ factor is negatively associated with only the ridership of TSPs.

\section{Discussion and Conclusion}

This study investigated the impact of TOSMD attractiveness factors (the independent constructs) on the ridership of shopper passengers using transit stations near TOSMDs (the dependent constructs), to inform and potentially enhance the existing forecasting models of station ridership and increase the economic sustainability of transit networks of the Dubai Metro Red Line. The study initially showed high volumes of ridership at stations near TOSMDs (refer to Fig. 4).

The independent constructs were categorised into (1) internal factors (product, price, place, promotion, people, physical evidence, and process), and (2) external factors (density, diversity, urban design, design accessibility, and distance). The 700 shopper passengers representing the dependent construct were categorised into resident shopper passengers (RSPs), and tourist shopper passengers (TSPs), refer to Table 1.

The study's PCA identified 12 independent constructs of TOSMD attractiveness factors that contributed to the dependent construct of ridership at transit stations near TOSMDs in the form of shopper passenger ridership using those transit stations. The cumulative percentage of variance explained in this relationship was $75.07 \%$, with reliability of 0.821 , and attractiveness factors with reliability above 0.7 for each construct shown in Table 2. The table showed all shopper passengers' scoring of a TOSMD's internal attractiveness factors of product, price, place, promotion, people, physical evidence, and process. Also, it showed all shopper passengers' scoring of a TOSMD's external attractiveness factors of density, diversity, urban design, destination accessibility, and distance, where a score of four identified an important factor. Additionally, the results in Table 1 showed differences in scoring of TOSMD attractiveness factors between RSPs and TSPs. All shopper passengers showed an agreement to use a metro station close to a mall mainly because there is walking access from the station to the mall $(M=4.090$, $\mathrm{SD}=0.997)$.

The study also presented a SEM model that explained the relationship between the identified independent constructs of TOSMD attractiveness factors and the dependent variable of shopper passenger ridership using metro stations near TOSMDs. The model was initially validated and 
Table 2 TOSMD factors impacting shopper passenger ridership

\begin{tabular}{|c|c|c|c|c|c|c|c|c|c|c|c|c|c|c|}
\hline Item $\backslash$ Factor & & 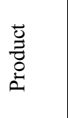 & 兽 & $\frac{\mathscr{m}}{\pi}$ & 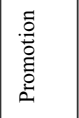 & $\begin{array}{l}\frac{0}{2} \\
\frac{0}{0} \\
2\end{array}$ & 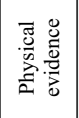 & 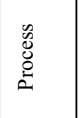 & 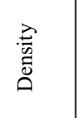 & 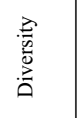 & 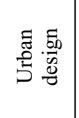 & 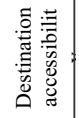 & 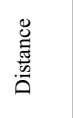 & 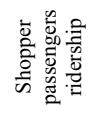 \\
\hline $\begin{array}{r}\text { Eigenvalue } \\
\text { Cronbach } \alpha \\
\text { Total variance explained (\%) } \\
\end{array}$ & $\begin{array}{r}0.821 \\
75.074 \\
\end{array}$ & \begin{tabular}{l|l|}
2.017 \\
0.818 \\
5.889 \\
\end{tabular} & $\begin{array}{l}1.51 \\
0.749 \\
5.576 \\
\end{array}$ & $\begin{array}{l}1.335 \\
0.787 \\
5.529 \\
\end{array}$ & $\begin{array}{ll}1.256 \\
0.757 \\
5.494 \\
\end{array}$ & $\begin{array}{l}3.333 \\
0.839 \\
6.270 \\
\end{array}$ & \begin{tabular}{ll|}
1.562 \\
0.789 \\
5.637 \\
\end{tabular} & \begin{tabular}{ll|}
4.433 \\
0.762 \\
6.514 \\
\end{tabular} & $\begin{array}{l}6.069 \\
0.877 \\
6.952 \\
\end{array}$ & $\begin{array}{l}2.56 \\
0.774 \\
5.898 \\
\end{array}$ & $\begin{array}{l}1.921 \\
0.809 \\
5.856 \\
\end{array}$ & \begin{tabular}{ll|}
0.877 \\
0.703 \\
4.879 \\
\end{tabular} & $\begin{array}{l}1.352 \\
0.751 \\
5.538 \\
\end{array}$ & $\begin{array}{l}1.054 \\
0.712 \\
5.042 \\
\end{array}$ \\
\hline Item & $\frac{\text { Code }}{q 0020 X}$ & 0.825 & & & & & & & & & & & & \\
\hline A variety in product quality present & $\mathrm{q} 0021 \mathrm{X}$ & 0.858 & & & & & & & & & & & & \\
\hline $\begin{array}{l}\text { Presence of fun and entertainment activities in the mall } \\
\text { (e.g. gaming arcade) }\end{array}$ & $\mathrm{q} 0022 \mathrm{X}$ & 0.814 & & & & & & & & & & & & \\
\hline Prices are appropriate to my income & $\mathrm{q} 0023 \mathrm{X}$ & & 0.756 & & & & & & & & & & & \\
\hline Overall price level in the mall & $\mathrm{q} 0025 \mathrm{X}$ & & 0.801 & & & & & & & & & & & \\
\hline Comparatively low prices & q0026X & & 0.775 & & & & & & & & & & & \\
\hline Size of the mall & $\mathrm{q} 0027 \mathrm{X}$ & & & 0.714 & & & & & & & & & & \\
\hline Average size of shops & $\mathrm{q} 0028 \mathrm{X}$ & & & 0.860 & & & & & & & & & & \\
\hline Number of shops & q0029X & & & 0.774 & & & & & & & & & & \\
\hline Promotional campaigns in the mall & $\mathrm{q} 0031 \mathrm{X}$ & & & & 0.829 & & & & & & & & & \\
\hline Organising events in the mall (e.g. shows) & $\mathrm{q} 0032 \mathrm{X}$ & & & & 0.718 & & & & & & & & & \\
\hline Loyalty programs & q0033X & & & & 0.794 & & & & & & & & & \\
\hline Staff friendliness and helpfulness & $\mathrm{q} 0035 \mathrm{X}$ & & & & & 0.799 & & & & & & & & \\
\hline Staff knowledge and training & q0036X & & & & & 0.788 & & & & & & & & \\
\hline Availability of customer service & q0037X & & & & & 0.854 & & & & & & & & \\
\hline Lack of crowdedness in the mall & $\mathrm{q} 0039 \mathrm{X}$ & & & & & & 0.792 & & & & & & & \\
\hline Comfortable controlled temperature & $\mathrm{q} 0041 \mathrm{X}$ & & & & & & 0.841 & & & & & & & \\
\hline Atmosphere in the mall (e.g. music and lighting) & $\mathrm{q} 0042 \mathrm{X}$ & & & & & & 0.785 & & & & & & & \\
\hline Ease of reaching the mall (e.g. directions) & $\mathrm{q} 0043 \mathrm{X}$ & & & & & & & 0.657 & & & & & & \\
\hline $\begin{array}{l}\text { Ease of finding a desired store inside the mall (e.g. Virgin } \\
\text { store) }\end{array}$ & $\mathrm{q} 0044 \mathrm{X}$ & & & & & & & 0.799 & & & & & & \\
\hline $\begin{array}{l}\text { Ease of finding a desired product inside the mall (e.g. } \\
\text { iPhone mobiles) }\end{array}$ & $\mathrm{q} 0045 \mathrm{X}$ & & & & & & & 0.794 & & & & & & \\
\hline $\begin{array}{l}\text { Crowdedness and compactness of buildings around the } \\
\text { mall }\end{array}$ & $\mathrm{q} 0047 \mathrm{X}$ & & & & & & & & 0.872 & & & & & \\
\hline $\begin{array}{l}\text { Total population in the neighbourhood around the } \\
\text { shopping mall }\end{array}$ & q0048X & & & & & & & & 0.794 & & & & & \\
\hline High number of shops surrounding the shopping mall & q0050X & & & & & & & & 0.821 & & & & & \\
\hline $\begin{array}{l}\text { The need for mixed residential and commercial buildings } \\
\text { around the shopping mall }\end{array}$ & $\mathrm{q} 0051 \mathrm{X}$ & & & & & & & & & 0.772 & & & & \\
\hline $\begin{array}{l}\text { Availability of scenic and recreational areas around the } \\
\text { mall (e.g. water fountain) }\end{array}$ & $\mathrm{q} 0052 \mathrm{X}$ & & & & & & & & & 0.852 & & & & \\
\hline $\begin{array}{l}\text { Availability of community services area around the } \\
\text { shopping mall (e.g. government services) }\end{array}$ & $\mathrm{q} 0053 \mathrm{X}$ & & & & & & & & & 0.684 & & & & \\
\hline $\begin{array}{l}\text { Availability of safe and air-conditioned walkways around } \\
\text { the mall }\end{array}$ & $\mathrm{q} 0055 \mathrm{X}$ & & & & & & & & & & 0.826 & & & \\
\hline Availability of parking facilities & $\mathrm{q} 0057 \mathrm{X}$ & & & & & & & & & & 0.813 & & & \\
\hline Availability of clear signage around the mall & $\mathrm{q} 0058 \mathrm{X}$ & & & & & & & & & & 0.850 & & & \\
\hline $\begin{array}{l}\text { Availability of walking access around the mall (e.g. } \\
\text { pedestrian crossings, bridges and tunnels) }\end{array}$ & q0059X & & & & & & & & & & & 0.751 & & \\
\hline $\begin{array}{l}\text { Access to facilities and amenities around the shopping } \\
\text { mall (e.g. hospitals) }\end{array}$ & $\mathrm{q} 0060 \mathrm{X}$ & & & & & & & & & & & 0.831 & & \\
\hline Access to downtown /or city centre & q0061X & & & & & & & & & & & 0.707 & & \\
\hline Proximity of shops in the area around the mall & $\mathrm{q} 0063 \mathrm{X}$ & & & & & & & & & & & & 0.766 & \\
\hline Proximity of a metro station & $\mathrm{q} 0064 \mathrm{X}$ & & & & & & & & & & & & 0.701 & \\
\hline Proximity of intercity public transport & $\mathrm{q} 0065 \mathrm{X}$ & & & & & & & & & & & & 0.754 & \\
\hline $\begin{array}{l}\text { I intend to use the metro station close to the mall because; } \\
\text { there is car traffic congestion in the area of the mall }\end{array}$ & q0068X & & & & & & & & & & & & & 0.752 \\
\hline $\begin{array}{l}\text { I intend to use the metro station close to the mall because; } \\
\text { there is lack of enough car parking spaces in the area of } \\
\text { the mall }\end{array}$ & $\mathrm{q} 0069 \mathrm{X}$ & & & & & & & & & & & & & 0.739 \\
\hline $\begin{array}{l}\text { I intend to use the metro station close to the mall because; } \\
\text { there is walking access from the station to the mall }\end{array}$ & $\mathrm{q} 0070 \mathrm{X}$ & & & & & & & & & & & & & 0.727 \\
\hline
\end{tabular}

Extraction method: principal component analysis

Rotation method: varimax with Kaiser normalisation

${ }^{\text {a }}$ Rotation converged in 7 iterations

$n=700$, Cumulative $\%$ of variance explained $=75.074$, Cronbach's alpha $=0.821$ 


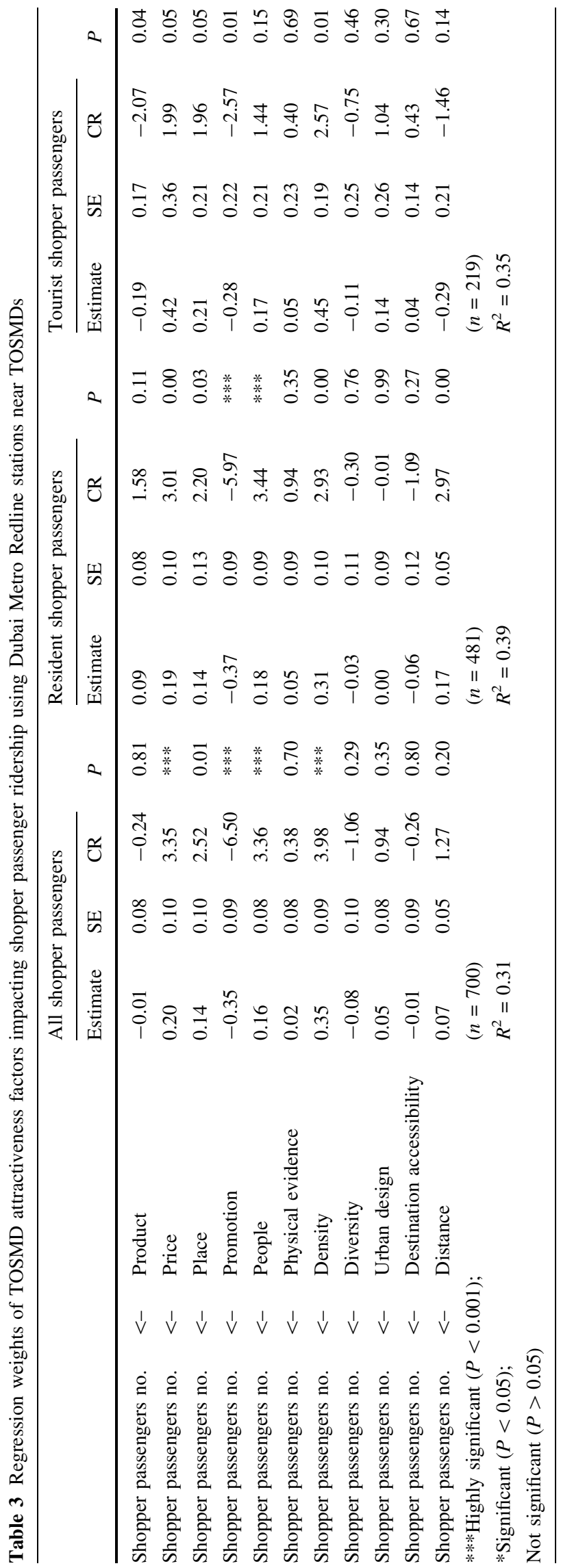

statistically considered to be fit. It confirmed that 11 of the 12 TOSMD independent constructs, namely product, price, place, promotion, people, physical evidence, process, density, diversity, urban design, destination accessibility, and distance, were associated with the ridership shopper passengers using metro stations near TOSMDs. The process factor was later eliminated, as its predicting items were distributed to other reflective factors, namely urban design and physical evidence factors, and therefore it became redundant (refer to Table 3 ).

An earlier study by the authors developed a conceptual framework that proposed a relationship between the latent construct of shopper passenger ridership at transit stations near a TOSMD and the independent constructs of TOSMD attractiveness factors [3]. This study has empirically supported and clarified the impact of the identified factors in the case of the Dubai Metro Red Line, with the exception of the process attractiveness factor. It provided statistically fit outcomes explaining the impact of the 11 factors on the number of shopper passengers (residents and tourists) for the Dubai Metro Red Line (refer to Table 3). The result of the study is also in line with previous urban transport planning studies, postulating that there is an interrelationship between railway stations and their context, namely TOSMDs [30, 77], and retail and marketing studies indicating that the level of congestion is likely to be higher with the broader assortment of services and products provided by larger shopping malls [78].

The study contributes to the transit urban planning literature by providing a practical implementation and a demonstration identifying and clarifying the impact of TOSMD attractiveness factors on ridership at transit stations near TOSMDs. Shopper passenger ridership contributes to the ridership at those stations in isolation from other stations not near TOSMDs in the same line and service context. However, the attractiveness factors of TOSMDs vary from one context to another (refer to Sect. 2.4). As can be seen in Table 3, it identified five independent TOSMD attractiveness constructs, including price, place, people, density, and promotion. These five constructs explained $31 \%$ of the dependent construct of shopper passenger ridership using the Dubai Metro Red Line stations near TOSMDs $\left(r^{2}=0.31, P>.05\right)$.

As an insight into the five identified constructs, the price construct was explained by comparatively low prices and overall prices in the mall. Furthermore, the respondents identified a high level of agreement $(M=4.223)$ that the pricing in the mall was appropriate to their income. Not unexpectedly, the price construct showed a higher level of significance to resident shopper passengers than tourist shopping passengers, which would be explained by residents' knowledge of price, and tourists being less conscious of price. The place construct had the lowest level of 
significance of the five constructs, which could be explained by the expectation of shoppers that shopping malls would cover large areas, and indicates that the respondents were comfortable with the experience of shopping in larger spaces where there is less shopper congestion. Within the people construct which was rated very high $(M=4.294)$, customer service was very highly considered $(M=4.471)$, followed by staff knowledge and training $(M=4.231)$ and then staff friendliness and helpfulness. The respondents did not rate the issue of the density of shops and population in the area surrounding the mall importantly in the descriptive data, but this may be explained by greater shopper focus on the shopping mall than the surrounding area.

The promotion construct was the only construct shown to be negatively correlated with shopper passenger ridership. This outcome can be accepted, as some shoppers may prefer to avoid Dubai mall crowding, e.g. on New Year's Eve when there is a fireworks event.

Additionally, the product construct (explained by the presence of a cinema, and the fun and entertainment activities, e.g. gaming arcade in the mall) was found to be negatively associated with the ridership of tourists and positively correlated for residents. This result can be explained by the fact that tourists are less motivated to attend cinemas and activities, as this was not their primary reason for travel to Dubai. Similarly, the distance construct (explained by the proximity of a metro station and proximity to intercity public transport) was found to positively impact only the ridership of residents but negatively impact ridership for tourists. This result can be explained by the fact that since residents live in Dubai, they rate the issues of proximity highly.

The five identified TOSMD attractiveness factors can be accepted, as Dubai uniquely has more than 65 malls, while its area is only $4000 \mathrm{~km}^{2}$. As a result, shopping mall competition is expected to be high. Therefore, the five identified TOSMD attractiveness factors and their explanatory items reflect attributes that allow a shopping mall to outperform its competitors, i.e. in the form of comparatively low prices, staff friendliness, customer service, etc.

As identified in the literature, the impact of TOSMD attractiveness factors has not been adequately considered in passenger forecasting models (PFMs), which have focused on factors such as the association between commercial floor area and station boarding. Hence, there was a need to examine to what extent TOSMD attractiveness factors impact ridership in the form of resident and tourist shopper passengers boarding at transit stations near TOSMDs, in order to better optimise TOD and to increase the economic benefits of transit networks. The study identified critical TOSMD attractiveness factors and clarified their impact in the form of shopper passenger ridership contributing to the ridership at stations near TOSMDs for the Dubai Metro Red Line.

The study was limited in that the causal relationships were tested with a single case study using the seven Dubai Metro Red Line stations near TOSMDs. It did not investigate the reverse causal effect, which might have influenced the latent constructs identified in the study. Furthermore, personality traits, and date and time of the survey may have affected shopper passengers' perceptions of TOSMD attractiveness factors; however, the consistency in descriptive survey data between stations and residents and tourists provides some confidence in the trends. These limitations warrant further investigation and could be incorporated into the design of future studies and be repeated in other cities' transit networks.

Despite its limitations, the study provides urban policymakers and rail transit urban planners with a practical basis from which to clarify shopper passenger ridership (including residents and tourists) using a transit rail station near a TOSMD. Furthermore, it provides a potential means of enhancing the accuracy and comprehensiveness of existing forecasting models (used to forecast transit station ridership) by identifying and clarifying the impact of TOSMD attractiveness factors on ridership at transit stations near TOSMDs. In particular, the approach may provide an understanding of shopper passengers contributing to the ridership at those stations in isolation from other transit stations not near TOSMDs in the same line and service context. Therefore, it is considered useful for cities with existing or growing rail network stations seeking to understand the expected ridership impact of TOSMDs on nearby transit network stations in the form of added shopper passenger ridership flowing into stations near TOSMDs. This understanding is considered useful for effective TOD approaches to rail network and shopping mall patterns of development, and economic sustainability in the form of guiding private or government investment as to where the best results will be achieved when developing metro stations.

\section{Compliance with Ethical Standards}

Conflict of interest The authors declare that they have no conflict of interest.

Open Access This article is licensed under a Creative Commons Attribution 4.0 International License, which permits use, sharing, adaptation, distribution and reproduction in any medium or format, as long as you give appropriate credit to the original author(s) and the source, provide a link to the Creative Commons licence, and indicate if changes were made. The images or other third party material in this article are included in the article's Creative Commons licence, unless indicated otherwise in a credit line to the material. If material is not included in the article's Creative Commons licence and your intended 
use is not permitted by statutory regulation or exceeds the permitted use, you will need to obtain permission directly from the copyright holder. To view a copy of this licence, visit http://creativecommons. org/licenses/by/4.0/.

\section{References}

1. Cushman \& Wakefield (2016) European shopping centre development report: November 2016. http://bpcc.org.pl/uploads/cke ditor/attachments/10749/european_shopping_centre_develop ment_report_nov_2016.pdf. Accessed 18 Aug 2017

2. Cushman \& Wakefield (2017) U.S. Shopping center marketbeat: Q2 2017. http://www.cushmanwakefield.com/ /media/reports/ corporate/MarketBeat\%20Reports/2017/Q2\%20US\%20Market Beat/CW_US_ShoppingCenter_MarketBeat_Q2_17.pdf. Accessed 14 Aug 2017

3. Abutaleb A, McDougall K, Basson M, Hassan R, Mahmood MN (2019) Towards a conceptual framework for understanding the attractiveness of rail transit-oriented shopping mall developments (TOSMDs). Urban Rail Transit. https://doi.org/10.1007/s40864019-00112-4

4. Farrag DA, El Sayed IM, Belk RW (2010) Mall shopping motives and activities: a multimethod approach. J Int Consum Mark 22(2):95-115. https://doi.org/10.1080/08961530903476113

5. Kok HJ (2007) Restructuring retail property markets in Central Europe: impacts on urban space. J Hous Built Environ 22(1):107-126. https://doi.org/10.1007/s10901-006-9068-z

6. Higgins CD, Kanaroglou PS (2016) A latent class method for classifying and evaluating the performance of station area transitoriented development in the Toronto region. J Transp Geogr 52:61-72. https://doi.org/10.1016/j.jtrangeo.2016.02.012

7. Taylor BD, Fink CN (2003) The factors influencing transit ridership: a review and analysis of the ridership literature. University of California Transportation Center

8. Zhao J, Deng W, Song Y, Zhu Y (2013) Analysis of Metro ridership at station level and station-to-station level in Nanjing: an approach based on direct demand models. Transportation 41(1):133-155. https://doi.org/10.1007/s11116-013-9492-3

9. Chan S, Miranda-Moreno L (2013) A station-level ridership model for the metro network in Montreal, Quebec. Can J Civ Eng 40(3):254-262. https://doi.org/10.1139/cjce-2011-0432

10. Sohn K, Shim H (2010) Factors generating boardings at Metro stations in the Seoul metropolitan area. Cities 27(5):358-368. https://doi.org/10.1016/j.cities.2010.05.001

11. Kuby M, Barranda A, Upchurch C (2004) Factors influencing light-rail station boardings in the United States. Transp Res Part A Policy Pract 38(3):223-247

12. Chu X (2004) Ridership models at the stop level National Center of Transit Research. University of South Florida, Tampa

13. Cervero R (2006) Alternative approaches to modeling the traveldemand impacts of smart growth. J Am Plan Assoc 72(3):285-295

14. McNally MG (2000) The four step model institute of transportation studies. Center for activity Systems Analysis, University of California, Irvine

15. Gutiérrez J, Cardozo OD, García-Palomares JC (2011) Transit ridership forecasting at station level: an approach based on distance-decay weighted regression. J Transp Geogr 19(6):1081-1092. https://doi.org/10.1016/j.jtrangeo.2011.05.004

16. Choi J, Lee YJ, Kim T, Sohn K (2012) An analysis of Metro ridership at the station-to-station level in Seoul. Transportation 39(3):705-722. https://doi.org/10.1007/s11116-011-9368-3
17. Brès A (2014) Train stations in areas of low density and scattered urbanisation: towards a specific form of rail oriented development. TPR Town Plan Rev 85(2):261-272. https://doi.org/10. 3828/tpr.2014.16

18. Chakour V, Eluru N (2014) Analyzing commuter train user behavior: a decision framework for access mode and station choice. Transportation 41(1):211-228. https://doi.org/10.1007/ s11116-013-9509-y

19. Handy S (2005) Smart growth and the transportation-land use connection: What does the research tell us? Int Reg Sci Rev 28(2): $146-167$

20. Vessali KV (1996) Land use impacts of rapid transit: a review of the empirical literature. Berkeley Plan J. https://doi.org/10.5070/ BP311113054

21. Zhao J, Rahbee A, Wilson NHM (2007) Estimating a rail passenger trip origin-destination matrix using automatic data collection systems. Comput-Aided Civ Infrastruct Eng 22(5):376-387. https://doi.org/10.1111/j.1467-8667.2007.00494. $\mathrm{x}$

22. Sides PC (2012) Regression model ridership forecasts for Houston light rail. The University of Texas at Austin, Texas

23. Estupiñán N, Rodríguez DA (2008) The relationship between urban form and station boardings for Bogota's BRT. Transp Res Part A Policy Pract 42(2):296-306

24. Yao X (2007) Where are public transit needed-examining potential demand for public transit for commuting trips. Comput Environ Urban Syst 31(5):535-550

25. Boyle DK (2006) Fixed-route transit ridership forecasting and service planning methods. Transportation Research Board, Washington, D.C.

26. Quade PB (1996) Douglas Inc: transit and urban form. National Academy Press, Washington

27. Cao XJ, Mokhtarian PL, Handy SL (2009) The relationship between the built environment and nonwork travel: a case study of Northern California. Transp Res Part A Policy Pract 43(5):548-559

28. Kim S, Ulfarsson GF, Hennessy JT (2007) Analysis of light rail rider travel behavior: impacts of individual, built environment, and crime characteristics on transit access. Transp Res Part A Policy Pract 41(6):511-522

29. Khattak AJ, Rodriguez D (2005) Travel behavior in neo-traditional neighborhood developments: a case study in USA. Transp Res Part A Policy Pract 39(6):481-500

30. Zemp Stauffacher, Lang Scholz (2011) Classifying railway stations for strategic transport and land use planning: context matters! J Transp Geogr 19(4):670-679

31. Kwoka GJ, Boschmann EE, Goetz AR (2015) The impact of transit station areas on the travel behaviors of workers in Denver, Colorado. Transp Res Part A Policy Pract 80:277-287. https:// doi.org/10.1016/j.tra.2015.08.004

32. Canepa B (2007) Bursting the bubble: determining the transitoriented development's walkable limits. Transp Res Rec J Transp Res Board 1992:28-34

33. Murray AT, Davis R, Stimson RJ, Ferreira L (1998) Public transportation access. Transp Res Part D Transp Environ 3(5):319-328

34. O'Sullivan S, Morrall J (1996) Walking distances to and from light-rail transit stations. Transp Res Rec 1538:19-26

35. Albalate D, Bel G (2010) Tourism and urban public transport: holding demand pressure under supply constraints. Tour Manag 31(3):425-433. https://doi.org/10.1016/j.tourman.2009.04.011

36. Kotler P, Hamlin MA, Rein I, Haider DH (2002) Marketing Asian places: attracting investment, industry, and tourism to cities, states, and nations. Wiley, Hoboken 
37. Colomb C (2012) Planning, history and environment: staging the New Berlin: place marketing and the politics of urban reinvention post-1989, vol Book. Taylor and Francis, Milton Park

38. Eshuis J, Braun E, Klijn E-H (2012) Bottlenecks in place marketing and their effects on attracting target groups. Perm Study Group Public Nonprofit Mark 28-43

39. Gertner D (2011) Unfolding and configuring two decades of research and publications on place marketing and place branding. Place Brand Public Dipl 7(2):91-106

40. Gj Hospers (2011) Place marketing in shrinking Europe: some geographical notes. Tijdschrift voor economische en sociale geografie 102(3):369-375

41. Kavaratzis M (2007) City marketing: the past, the present and some unresolved issues. Geogr Compass 1(3):695-712

42. Kotler P, Gertner D (2011) A place marketing and place branding perspective revisited. In: Destination brands: managing place reputation, 3 edn. Elsevier Ltd., pp 33-53

43. Huff DL (1962) Determination of intra-urban retail trade areas. Real Estate Research Program, Graduate Schools of Business Administration, University of California

44. Nevin JR, Houston MJ (1980) Image as a component of attraction to intraurban shopping areas. J Retail 56(1):77-93

45. Wong G, Yu L, Yuan L (2001) SCATTR: an instrument for measuring shopping centre attractiveness. Int J Retail Distrib Manag 29(2):76

46. Wei Khong K, Sim Ong F (2014) Shopper perception and loyalty: a stochastic approach to modelling shopping mall behaviour. Int $\mathbf{J}$ Retail Distrib Manag 42(7):626-642. https://doi.org/10.1108/ IJRDM-11-2012-0100

47. Arslan TV, Sezer FS, Isigicok E (2010) Magnetism of shopping malls on young Turkish consumers. Young Consum 11(3):178-188. https://doi.org/10.1108/17473611011074250

48. Dahsh M, Dasa P (2014) Shopping mall preferences in easten region: implications for retail strategy. Prestige Int J Manag Res 7/8(2/1): 19

49. El-Adly M (2007) Shopping malls attractiveness: a segmentation approach. Int J Retail Distrib Manag 35(11):936-950. https://doi. org/10.1108/09590550710828245

50. Kushwaha T, Ubeja S, Chatterjee AS (2017) Factors influencing selection of shopping malls: an exploratory study of consumer perception. Vis J Bus Perspect 21(3):274-283. https://doi.org/10. 1177/0972262917716761

51. Tandon A, Gupta A, Tripathi V (2016) Managing shopping experience through mall attractiveness dimensions: an experience of Indian metro cities. Asia Pac J Mark Logist 28(4):634-649. https://doi.org/10.1108/APJML-08-2015-0127

52. Erkip F (2005) The rise of the shopping mall in Turkey: the use and appeal of a mall in Ankara. Cities 22(2):89-108. https://doi. org/10.1016/j.cities.2004.10.001

53. Ke Q, Wang W (2016) The factors that determine shopping centre rent in Wuhan, China. $J$ Prop Invest Finance 34(2):172-185. https://doi.org/10.1108/JPIF-04-2015-0021

54. Lee S, Yi C, Hong S-P (2013) Urban structural hierarchy and the relationship between the ridership of the Seoul Metropolitan Subway and the land-use pattern of the station areas. Cities 35:69-77. https://doi.org/10.1016/j.cities.2013.06.010

55. Hall DR (1999) Conceptualising tourism transport: inequality and externality issues. J Transp Geogr 7(3):181-188

56. Neuman WL (2011) Social research methods: qualitative and quantitative approaches, 7th edn. Allyn and Bacon, Boston

57. Veal AJ (2006) Research methods for leisure and tourism: a practical guide. Pearson Education, London
58. Jacobs H (2018) Why Dubai has so many malls. Business insider. https://www.businessinsider.com/why-dubai-has-so-many-malls2018-11. Accessed 13 Mar 2020

59. Portal TUAEG (2020) Abount Dubai. The United Arab Emirates' Government portal. https://u.ae/en/about-the-uae/the-seven-emi rates/dubai. Accessed 13 Mar 2020

60. Center DS (2020) Population. Dubai Statistics Center. https:// www.dsc.gov.ae/en-us/Pages/default.aspx. Accessed 13 Mar 2020

61. Department DE (2019) Dubai Economic report 2019. Dubai Economic Department

62. Yin RK (1981) The case study crisis: some answers. Adm Sci Q 26(1):58-65

63. Schofield JW (2002) Increasing the generalizability of qualitative research. Qual Res Companion 171-203

64. Yin RK (1994) Case study research: design and methods, 2nd edn. Applied Social Methods Research Series. Thousand Oaks (California): Sage Publications, Inc

65. Flyvbjerg B (2001) Making social science matter: why social inquiry fails and how it can succeed again. Cambridge University Press, Cambridge

66. Thomas R, Bertolini L (2014) Beyond the case study dilemma in urban planning: using a meta-matrix to distil critical success factors in transit-oriented development. Urban Policy Res 32(2):219-237. https://doi.org/10.1080/08111146.2014.882256

67. O'Neill WA, Ramsey RD, Chou J (1992) Analysis of transit service areas using geographic information systems. Transp Res Rec 1364:131-138

68. Zhao F, Chow L-F, Li M-T, Ubaka I, Gan A (2003) Forecasting transit walk accessibility: regression model alternative to buffer method. Transp Res Rec 1835:34-41

69. Kamruzzaman Md, Baker D, Washington S, Turrell G (2016) Determinants of residential dissonance: implications for transitoriented development in Brisbane. Int $J$ Sustain Transp 10(10):960-974. $\quad$ https://doi.org/10.1080/15568318.2016. 1191094

70. Cooper DR (2011) Business research methods. The McGrawHill/Irwin series in operations and decision sciences, 11th edn. McGraw-Hill/Irwin, New York

71. Guarte JM, Barrios EB (2006) Estimation under purposive sampling. Commun Stat Simul Comput 35(2):277-284. https://doi. org/10.1080/03610910600591610

72. Lai W-T, Chen C-F (2011) Behavioral intentions of public transit passengers - the roles of service quality, perceived value, satisfaction and involvement. Transp Policy 18(2):318-325

73. Lei PW, Wu Q (2007) Introduction to structural equation modeling: issues and practical considerations. Educ Meas Issues Pract 26(3):33-43

74. Bentler PM (1990) Comparative fit indexes in structural models. Psychol Bull 107(2):238

75. Bentler PM, Bonett DG (1980) Significance tests and goodness of fit in the analysis of covariance structures. Psychol Bull 88(3):588

76. Rabbanee FK, Ramaseshan B, Wu C, Vinden A (2012) Effects of store loyalty on shopping mall loyalty. J Retail Consum Serv 19(3):271-278. https://doi.org/10.1016/j.jretconser.2012.02.001

77. Castillo-Manzano JI, López-Valpuesta L (2009) Urban retail fabric and the metro: a complex relationship. Lessons from middle-sized Spanish cities. Cities 26(3):141-147. https://doi.org/ 10.1016/j.cities.2009.02.007

78. Rajagopal D (2009) Growing shopping malls and behaviour of urban shoppers. J Retail Leis Prop 8(2):99-118. https://doi.org/ 10.1057/rlp.2009.3 